\title{
Not in my face please. Stress caused by the presence of smokers in places with restorative qualities
}

Chamila Subasinghe

Curtin University, Australia

chamila_sad@yahoo.com

\begin{abstract}
Non-smokers' spatial transactions with smokers in semi-outdoor areas with restorative qualities have been investigated. In the process, the impact of smoking in break spaces on non-smokers' behavior in negotiating mutual spatial boundaries was studied. The areas with restorative qualities were defined as places where regular visitors spend their break time to relieve work-related stress or seek temporary relaxation. Regularly used as break areas, three covered-overhead walkways located in different building precincts in the same academic setting were sampled in order to elicit narratives relating to perceived environmental deprivation among regular visitors. In-depth, semi-structured interviews had the aim of eliciting and unfolding these narratives where they emerged as a result of different modes of environmental deprivation. Discourse analysis of the transcribed interviews led to a systematic distillation of five themes associated with the presence of smokers in the studied restorative settings. The study revealed that participating non-smokers had devised both control and coping mechanisms to deal with the smokers' behaviors, such as sending subtle non-verbal cues and repositioning their gaze. Moderated by furniture and landscape configuration, spaciousness, and visual and physical distance, smokers and non-smokers passively negotiated these spatial transactions in each of the respective walkways.
\end{abstract}

Keywords: smokers' presence, restorative environments, work-related stress, spatial negotiations

To cite this article:

Subasinghe, C. (2019). Not in my face please. Stress caused by the presence of smokers in places with restorative qualities, The Journal of Public Space, 4(I), 33-44, DOI I0.3289I/jps.v4il.564

This article has been double blind peer reviewed and accepted for publication in The Journal of Public Space.

c) (1) $\$$ This work is licensed under a Creative Commons Attribution - Non Commercial 4.0 International License https://creativecommons.org/licenses/by-nc/4.0/ 
Not in my face please

\section{Introduction}

People always come up to me and say that my smoking is bothering them...

Well, it's killing me.

- Wendy Liebman

Dialectically captured in Lebman's words, public smoking offers insights into an act of abject spatial-aspatial consciousness (Cross \& Hopwood, 2007). Although smoke-free workplace agreements assure the rights of non-smokers, smoking is being tolerated in some break areas outside the work environment. Hence, this study looked into somewhat little-known aspects of spatial negotiations between smokers and nonsmokers in areas with moderate restorative qualities. Furthermore, it naturalistically looked into migratory elements and mechanisms related to public smoking that occur in places where both smokers and non-smokers spend their break time on a regular basis (Lincoln \& Guba, 1985).

Very little evidence exists surrounding the impact of smoking in restorative environments, specifically on workers and other users spending time in academic settings. Even fewer studies have investigated structural factors that facilitate or impede the therapeutic qualities of such environments, especially when it comes to the potentially negative influence that the presence of smokers can have on these environments. Dissimilar to healthcare settings, the terms healing or restorative have not often been used in research literature to describe the workability of other specialised work environments, apart from a few notable cases in the financial sector (Dunham et al., 200I). However, where work-related stress is considered, not only in healthcare settings but also in other specialised work environments, specific positive outcomes could be potentially obtained via providing access to nature and its restorative qualities. Both active recreational and passive observational activities contribute to stress relief and subsequent attention restoration (Ulrich, 1999; Sargent, Williams, Williams, Johnson, 2017). What is largely unexplored, however, is how non-smokers perceive the presence of smokers in non-smokers' "places of escape" in academic settings where individuals aim to attain a temporary state of relaxation during their break time to assist them in dealing with day-to-day stress. Building on existing research, this study hypothesised that both physical and visual distance between smokers and non-smokers have the capacity to reduce stress caused by the presence of smokers, smoke, and cigarette butts. Furthermore, it also extended this hypothesis by projecting that spatial transactions among non-smokers could occur via movable furniture and landscape features where they facilitated the negotiation of visual and physical distance from smokers.

Although a growing body of research has examined the role of therapeutic or restorative environments in healthcare settings and assisted living facilities, few studies have focused on spatial negotiations in moderately therapeutic areas in the workplace, particularly in academic settings. Noticeably, this developing discourse has still not branched into the theme of smoking in areas where definitions of both restorativeness and publicness openly remain broad and diverse (Hartig, Kaiser, \& Bowler, 1997). However, in attention restoration theory, Kaplan and Kaplan, $(1989,200 I)$ proposed 
four factors of restorativeness; being away (a state that calls on mental content that is different from that which is ordinarily elicited); extent (the environment's content and structure, which can occupy the mind for a period long enough to allow directed attention to rest; fascination (effortless attention); and compatibility (relating to an individual's inclinations and the kinds of activities facilitated by a particular setting). Publicness, on the other hand, a slippery term, has been attributed to a hybrid of ownership, control, physical configuration, animation and civility (Varna, 20 I4). Fragmented literature on smoking in the domains of publicness and restorativeness largely remains an uncontested ground consisting of narrow specifications limited to micro-segments of social discourse. For example, a study concluded that the observation of smoking in public places including universities leads some youths to conclude that smoking is socially acceptable in community settings (Alesci, Foster, \& Blaine, 2003). Thrasher and Bentley (2006) assert that smoking among college students is influenced by their environment, which likely supports their perception of smoking as a normal, socially acceptable practice. Another study investigating impressions of smoking and experiences of disapproval surrounding public-smoking found that smokers are sensitive to the social disapproval that comes as a result of their actions (Louka, Maguire, Evans, \& Worrell, 2006). While disapproval from those close to them was accepted, disapproval from the general public was not. However, it is also probable that anti-smoking measures and associated disapproval of smoking affect perceptions of cultural norms around smoking among the general public (Nyborg \& Rege, 2003; Parry \& Platt, 2000). Kim and Shanhan (2003) found that smokers who have experienced unfavorable public sentiment are more willing to quit smoking than those who have not. They further suggest that by outlawing smoking in public and private places, "smokefree" acts not only protect non-smokers from second-hand smoke but also enforce behavioral changes among smokers. On the contrary, the smoking area in a restorative environment worked as a refuge where social interaction was not possible (Cerwén, Wingren \& Qviström, 2016).

According to studies, the universities from USA have reported that regular exposure to second-hand smoke compromised environmental quality and had a subsequent impact on the psychophysiological health of students and staff (Wolfson, McCoy, Sutfin, 2009). Further studies offer evidence on ways in which outdoor smoking near building entrances affect the quality of indoor spaces (Sureda, Fernandez \& Lopez, 20I3). Suggesting a somewhat sympathetic attitude towards outdoor smoking, respondents from a large Australian university felt that there should be places on campus for smokers to smoke (Burns, Hart, Jancey, Hallett, Crawford, \& Portsmouth, 2016). Irrespective of the presence of restorative qualities, both smokers and non-smokers chose outdoor over indoor when it came to offering designated places for smokers to smoke (Braverman \& Hoogesteger, Johnson, 2015; Loukas, Garcia \& Gottlieb 2006). Although limited, recent literature on public smoking has a substantial focus on vaping and e-cigarette related practices in public spaces. A recent study showed a difference between reported vaping in public and private places in the United Kingdom of Great Britain and Northern Ireland and Australia which have different regulatory environments for personal vaporizers. This study further concluded that the level of vaping in smoke-free public places reflects the regulatory environment and in addition that social acceptance of vaping increases with exposure and experience (Lee, Yong, Borland, Mcneill, \& Hitchman, 2018). Following the criminalisation of smoking in 
enclosed public places, smoking has been moved to areas with evening economy (Quercia, Schifanella, Aiello \& McLean, 2015).

\section{Subjects and Methodology}

A college campus setting was sampled to investigate the hypothesised association between alterations to the restorative qualities of a place frequented by workers for break-time relaxation and the presence of smokers in the venue at the same time. The three overhead walkways studied connected two masses of buildings within the same compound at a single storey height level above the ground. This elevation offered a broad range of vantage points and view corridors including pedestrian and vehicular movements, mature landscape, buildings with period architecture, and a few parking bays facing in at least two opposite directions. The walkways also contained a few removable seating options and spaciously organised plant containers along balustrades. All three of them were roofed with translucent claddings, which provided refuge from the year-round harsh sun and occasional torrential rain thus establishing an enclosure, yet an outdoor-like ambience.

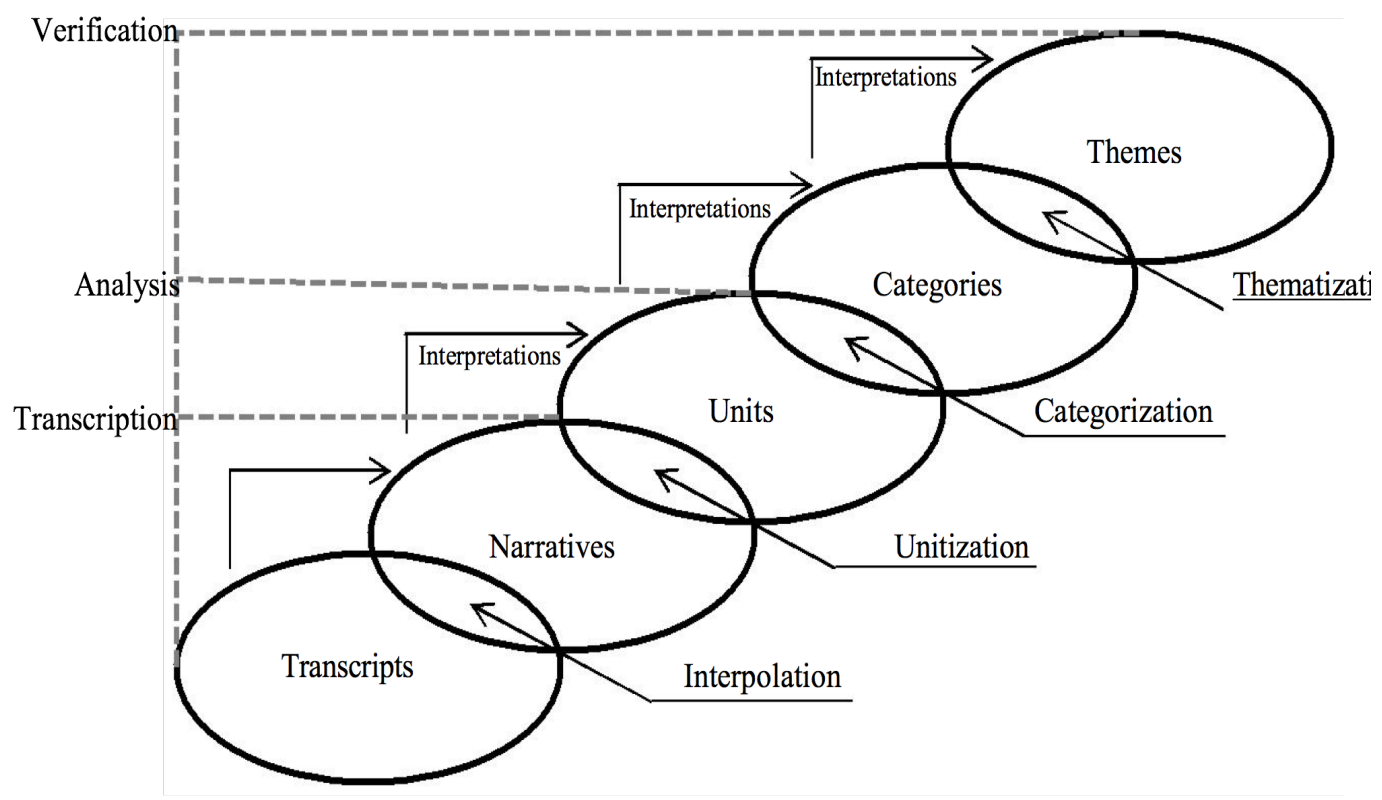

Fig. I Systematic acquiring of themes via the naturalistic-inquiry process (Subasinghe, 20I2)

Thirty-four non-smokers who frequent the sampled areas for various types of socialising such as lolling, loitering, strolling, reading, and making telephone calls were recruited through their employers. In-depth, open-ended cognitive interviews were conducted among the participants, who volunteered to make recommendations for improving the restorative qualities of the overhead walkways. Four of the 34 subjects did not want to extend the interview with a view to making recommendations because they believed smokers should be utterly banned from the area in order to secure the restorative nature of the walkways. A second set of interviews was conducted to verify prototype 
themes that emerged from the first set of interviews. The subjects were probed to sort the most representative units from respective interview transcripts into prototype themes with a resulting matching rate of 92 per cent between author's choice and subjects' choice. At the beginning of the first set of interviews, the interviewer asked a grand tour type question such as "tell me what a typical day is like for you?" to open up an avenue for a rapport interview, establishing the interviewer as a listener rather than as an interrogator (Lincoln \& Guba, 1985; Klein, Calderwood, \& Macgregor, 1989;Massarik, 1981). This was intended to elicit as much free recall from participants as possible while minimising threats to indeterminacy. Using rapport-building statements and questions such as "tell me more", "what else?", "so/then" and "sounds interesting", the interviewer elicited environmental perceptions related to stress relief, again with open-ended questions such as "how often do you use outdoor environments to chill out?" Based on the supposition that human activities and experiences are essentially categorical in nature, interviews were unitised and subsequently coded by the author into somewhat distinctive categories (Canter, Brown, \& Groat, 1985). As diagrammed in Figure I, these recurring categories were further sorted into emerging themes to curate their essence into achieving self-standing status (Subasinghe, 20I2).

\section{Discussion and Results}

The following discourse analysis details the outcome of the transcribed interviews that led to the taxonomisation of five themes associated with the presence of smokers in the studied restorative settings. However, a nondescript yet potential theme emerged from discussions with a few participants who quit smoking a few years ago. They had a somewhat sympathetic attitude towards smokers and strongly believed in protecting exclusive areas for them. The majority of respondents (87\%) expressed deep displeasure towards smokers' use of the walkways and would likely visit the area more frequently if smokers were "out of my face". The rest of the respondents thought that the residual effects of smoking, such as the presence of cigarette butts, smoke in the air, and sharing space with "strangers", was more harmful to the ambience of the walkways than the actual presence of smokers. As diagrammed in Figure I, the following themes which emerged from the discourse analysis are organised according to idioms or their approximations suggested by the participants in their efforts to represent the nature of a particular deprivation.

Not in My Face. Response to the presence of smokers was heavily moderated by how familiar the non-smokers were with the smokers. As long as smoke or smokers were not in direct contact with them, the non-smokers tolerated the smokers based on their level of familiarity, either professional or personal. Friends and colleagues were seen as a less intrusive category which deserved "understanding" or some level of sympathy. In contrast, professional contacts were treated as a somewhat intrusive cohort, though still deserving of respect. However, for both categories, visual or physical distance was critical because walkway users found that disruptive levels of exposure to smoke lessened their feelings of understanding or respect. While non-smokers' socialising with familiar smokers was restricted to the exchange of a few words, non-smokers engaged each other in lengthier social behaviors that involved chatting, listening to music, 
exchanging food, sharing reading materials, and a limited amount of intragroup activities. Participant 16 stated:

"As long as they are far away enough from me so that I can't smell the smoke, I'm fine, but some days no matter how far away you are, man, you seriously can smell those folks. A couple of my friends also come here for smoking, but they don't really bug me that much. We don't really socialize here, just nodding and waving at each other! I often see a few of my bosses here, too. I don't show my sour face to them. It's easy to stay away from them as much as possible, so I make it a point to either leave the place or to distance myself from them. So we hardly notice each other."

While professional and personal obligations did not moderate non-smokers' ultimate preference that smokers not inhabit the same space, their tolerance level was somewhat moderated. The non-smokers employed simple ways to share the same space with their friends and business contacts who smoke, such as physical and visual distancing. Distance seemed to help them dissociate unfriendly habits from their relationships. Such tactics helped non-smokers easily escape smokers without compromising their personal and professional affiliations. However, when several occupants used the overhead walkways at the same time, especially non-smokers, maintaining adequate distance from the smoke was more difficult and further challenged coexistence between the two groups.

Burning Your Bridges. Territorialisation of the overhead walkways was another way non-smokers controlled the length of stay of smokers. Quite often this was launched as a spontaneous group action by the non-smokers. When non-smokers outnumbered smokers, non-smokers tended to extend their territory to corners normally occupied by smokers, thus obstructing access to ashtrays in the area. Typical reactions to this kind of territorial superiorisation had the smokers leaving the walkways, shortening their stay, or finding alternative locations for smoking.

When "smoking corners" were empty, it was observed that the non-smokers stuck to their usual areas, even though many of them were crowded together. Participant II averred:

"I have my favorite corner and always make sure that I stay away from smoking spots and ashtray bins. Those places are just gross. No matter how often they empty the bins, they stink. When we have a whole bunch of us together, I feel like claiming the place for ourselves. Most of the time when we hang around in their area, they smoke like crazy fast and then disappear in no time. I think they kind of understand what they are doing is not cool and if they still want to smoke here that they have to do it really quick."

Planters, furniture and suchlike further moderated the perceived distance from smokers. Furthermore, temporary spatial demarcations with movable furniture were established where additional reinforcements were needed. Extending the designated 
areas for non-smokers indicated that reclaiming their original space for stress relief and passive socialising was important. The occupation of corners usually inhabited by smokers was seen as more than a spontaneous extension of boundaries; it was also a reaction to the negative use of a place with restorative qualities. Arguably, because this was a group action, spatial transactions between the two groups might have a bearing on broader environmental stress in the workplace.

Sending a Message. Sending a subtle non-verbal message similar to a broken cough was often practiced among the walkway users who felt strongly about the presence of smokers. When the non-smokers were desperate for a break in a semi-secluded outdoor type environment, especially after stressful work in studios, the presence of smokers made them feel more vulnerable. Upon entering the walkways, a direct view of smoker-corners immediately caused adjustments in the non-smokers' behavior. Such altered behavior, including sending non-threatening clues, required varying degrees of time and coping strategies depending on the intensity of the scene in the smokercorners. More smokers caused them to be more cautious or have more controlled reactions than a few smokers or a single smoker did. Participant 29 commented:

"No one wants them there; they are just an unfriendly, gross bunch of people grouped in the corners of the bridge. Sometimes there are so many that they fill the whole space. I have my way of sending the message, but sometimes they don't care. They act like they haven't heard us, so I have to cough fanatically to make the message clear."

As Participant 29 demonstrated, non-smokers also expressed displeasure with smokers through their descriptions of the smokers' physical appearance and behavioral attitudes. Additionally, smokers' occupation of the corners at the very ends of the walkways, as well as their grouping behaviors such as socialising while smoking, threatened nonsmokers' sense of privacy and safety. The non-smokers further felt that the walkways were relatively tight when smokers were present compared to the sense of space they experienced in the absence of smokers. This perceived crowdedness may have led the non-smokers to send non-threatening, but distinct messages to limit the smokers' possible extension of their unofficial spatial boundaries or to shorten the length of their stay.

Escaping to Smoke. For non-smoking users of the overhead walkways, the transition point from indoors to outdoors signified an exit from their demanding work in "walled" interiors into more accommodating open "interiors". The concentration of smokers in the partly secluded corner immediately next to the exit door caused the non-smokers' to lower their expectations. The smoke itself intervened with their escape route more than the actual presence of the smokers. Alarming levels of smoke were not only considered as a severe threat to the quality of the air space, but also an exploitation of the non-smokers' extended tolerance. According to Participant 21:

"They smoke so close to the entrance so that you have to practically walk 
through the smoke. The smell takes away the quality of the place. When I'm on the bridge I do pay attention to smokers, but I rather prefer that they don't look at me. It does really irritate me when they don't give us an escape route even. I can deal with the stupidity of risking your own life, but not ignorance towards other people's lives and personal space. Blowing clouds in your face is not just a stink issue, but it's about not having respect for people who really care for this space."

Moreover, the non-smokers felt that the quality of the transitional space between the interior and exterior was compromised because of what they call the three S's: the Smoke, the Smell, and the Society among smokers. While the smoke issue was perceived as a lack of respect toward non-smokers, the smell was considered to compromise the restorative quality of the space. The socialising (society) among smokers emulated a notion of normalcy of smoking, which non-smokers felt was utter social misconduct that would eventually grow into a larger issue regarding the legitimisation of smoking in healing environments. As long as smoking was done in an apologetic manner with minimal visual or physical interference with the intended purpose of the space, the non-smokers did not push for intervention. Even though the experience of smoke and smell has no significant effect outdoors, the society or grouping of the smokers added weight to the overall undesirable psychological presence of the smoke and smell.

But Is Not Butt. Most of the non-smokers who acknowledged smokers' right to use the walkway agreed that scattered cigarette butts caused reactionary levels of environmental degradation. Furthermore, these discarded cigarette butts were viewed as an abuse of the restorative spatial qualities of the skywalk, which added to the stress of the non-smokers whose prime purpose for visiting the space was stress relief. Even scattered cigarette butts that had fallen out of bins were seen as the direct responsibility of the smokers rather than accidental in nature due to misplaced lids or mishaps during cleaning. Spatial negotiations might have occurred in the event of a direct violation of "rules" such as openly throwing butts elsewhere, not disposing of them properly into bins, or letting them fall on the floor. In addition, scattered cigarette butts were seen as a deliberate mode for smokers to extend their spatial boundaries or spatial claim for smoking. Participant I5 noted:

"I understand they too need to chill out here, but dare they not throw cigarette butts all over the place. Everybody has their own limits of eating (bearing) consequences from other people's misbehaviors. Well, when you don't take care of yourself, one can't expect them to be sensitive about a place. You would notice some of those people who trash this (walkway) are the people who have very clean offices or work stations, so it's clear that they don't see this as a place that means something to a lot of people. We have more tolerance than they do, but it might explode at any moment and that will be really unpleasant." 
Participant I5's feeling seems to be that of an unspoken, but mutually agreed pact which had been disrespected. The majority of the non-smokers expected smokers to appreciate their tolerance at least by keeping the place free from the remains of smoking. The notion that something that should not be tolerated at all, has gone above and beyond its bearable limits, consequently led to a feeling of resentment. Part of the resentment might be a result of building administrators not having set specific rules and regulations or even general instructions regarding smoking or designated smoking areas. There was a clear feeling that the issue could even lead to physical confrontations as a direct reaction to environmental deprivation. The noted difference between the treatment of personal and public spaces was also seen as a deliberate exploitation of the skywalk by the smokers.

\section{Conclusions}

Unless the work itself is about health and wellness, work-related, day-to-day stresses tend not to receive much attention and thus, rarely get reported. Little to no research evidence links occupational stress relief-mechanisms with associated spatial needs in areas for temporary stress relief. Even fewer research reports exist on how microspatial responses resulting from certain behaviors such as smoking in common areas with moderate restorative qualities affect relief-mechanisms. Therefore, this study has attempted to build a potential nexus between occupational stress relief in areas with moderate restorative qualities and various user adaptations to public smoking in such areas.

The non-smoker participants expressed an apparent uneasiness regarding the presence of smokers in the walkways, their place of temporary relief from a stressful day at work. On average, the non-smokers experienced greater degrees of negative stress-i.e. feeling tense, on edge, discouraged, and annoyed-when smokers were present than when smokers were not present. Alternatively, when smokers were not present, the occurrence of all restorative emotions-i.e. feeling relieved, elated, comfortable, and rejuvenated-mentioned during the interviews were considerably higher.

Another normative aspect of the discourse analysis revealed several potentially meaningful themes attached to the concepts of publicness and restorativeness specific to the studied three overhead walkways. The majority of the overhead walkway users perceived the walkway as a moderately restorative "in-between" environment, with regard to transition between the two sections of the compound as well as the restorative qualities affected by the presence of smokers. The elevation of the walkway allowed for a degree of separation from a heavily choreographed groundfloor environment while maintaining a controlled yet uninterrupted and direct access to work areas. The ambience of the walkway enables passive isolation from both the demanding atmosphere of an academic setting and the hustle and bustle of groundfloor traffic. Apparently, users sought its solace when stressed with work-in-progress or "yet to complete" tasks, when running behind in their schedules, when facing unmanageable amounts of work, or when dealing with personal, non-work-related stressors. Familiarity among the users and tolerance levels played a critical role in determining length of the stay and coping mechanisms as demonstrated in Figure 2. For example, when aiming for a comfortable stay in the presence of familiar smokers, 
non-smokers were inclined to entertain a high level of tolerance by adopting coping strategies such as visual and physical distancing. On the other hand, if the majority of the smokers were unfamiliar, non-smokers may attempt visual and physical distancing followed by a limited stay. Apparent low tolerance levels caused by such distancing might also result in the sending of subtle or direct messages to smokers as discontentcues of environmental deprivation.
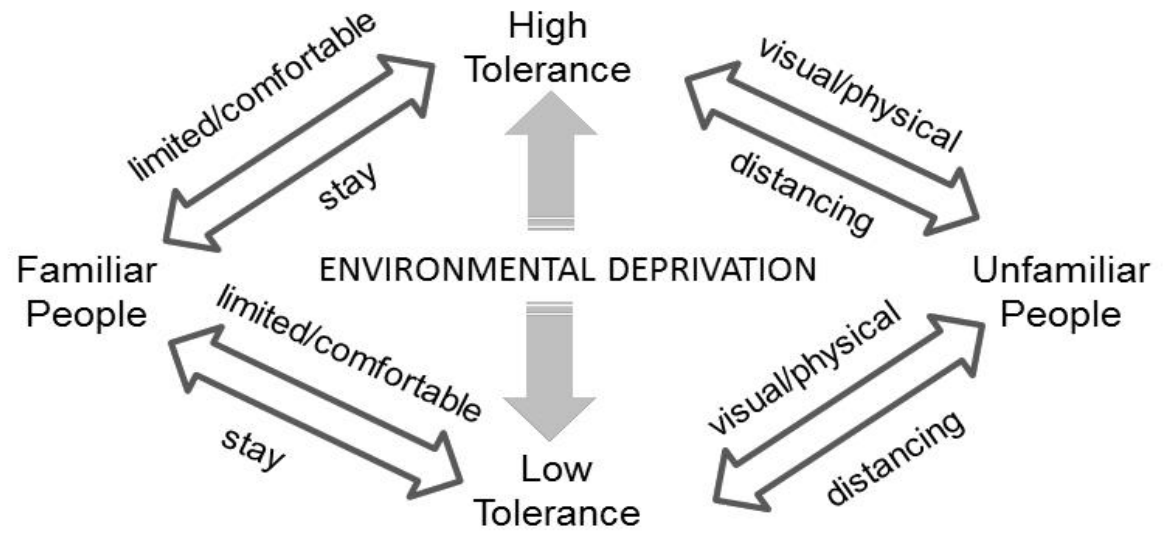

Fig. 2 Relationships between length of stay vs. coping mechanism and familiarity vs. tolerance level

Even though the general attitude of the non-smokers towards smokers was somewhat hostile, they accommodated the notion of negotiated or conditional sharing with visitors to the walkways. The awareness of smoking as a form of stress relief for smokers did not directly mediate such negotiations for the non-smokers. On the contrary, the non-smoker users felt exploited, cheated, and trapped rather than being provided an opportunity to "get away" in the presence of smokers. These feelings were particularly acute when non-smokers were forced to walk through smoke. Common themes that emerged from the analysis included feelings of smokers as abusers or exploiters who only spend time in the walkway until their cigarettes burn off with no sense of attachment or belongingness to the environment. For a considerable portion of the study population, the litter from smoking made a greater impact on the degradation of the overall restorative quality than the presence of the smokers did.

The physical and visual distance between smokers and non-smokers was critical above all. Distance was moderated by furniture and landscape features found on the walkway, and the perceived visual and physical distance significantly affected stress levels. Even if the non-smokers' tolerance level reached an actionable level, the window for any spatial confrontation was quite slim. In such a scenario, instead of smokers altering their behaviors or terminating their visits to the space, non-smokers tend to abandon or limit the length of their stay. This might be considered as an extreme method for nonsmokers to physically and visually distance themselves from smokers due to compromised restorative qualities in the environment.

Instead of requesting complete prohibition of smoking in the walkway, the majority of the respondents were considerate enough to suggest transient spatial boundaries for 
smoking. One respondent elaborated on this idea and even pointed out a tentative location for the proposed area by the side of the main building. Other suggestions included placing plant containers similar to existing ones at both sides of the walkway, introducing artwork, such as sculptures and getting rid of cigarette bins. More facilities for seating -including benches rather than movable chairs-could facilitate a more negotiable space. These proposals strongly suggest creating a static spatial configuration in the area to preserve its restorative qualities and make smokers less noticeable among the larger group. These findings have the potential to inform the design of public space in the urban context via the ordering of spatial zones to achieve visual distancing, leveling the environmental deprivation across different sectors of society. The themes that emerged from the discourse analysis revealed an inverse relationship between the perceived level of stress relief reported by non-smoker participants and the presence of smokers. This inconclusive yet apparent relationship supports the key hypothesis on the effects of compromised restorative qualities arising from altered environmental conditions caused by smoking, including smokers, smoke, and cigarette butts. In addition to a multiple sorting of the results within the same sample group, the study proposes a triangulation of the results via a statistical analysis of a larger sample group to ensure transferability.

\section{References}

Alesci, N. L., Forster, J. L., Blaine, T. (2003). Smoking visibility, perceived acceptability, and frequency in various locations among youth and adults, Preventive medicine, 36, 272-28I.

Braverman, M, T., Hoogesteger, L, A., Johnson J, A, 2015). Predictors of support among students, faculty and staff for a smoke-free university campus. Preventive Medicine 7I, II420.

Burns, S., Hart, E., Jancey, J., Hallett, J., Crawford, G. and Portsmouth, L. (20I6). A cross sectional evaluation of a total smoking ban at a large Australian university. BMC Research Notes, $9(1)$.

Canter, D., Brown, J., Groat, L. (1985) "A multiple sorting procedure for studying conceptual systems" In M. Brenner, J. Brown, \& D. Canter (eds.), The research interview: uses and approaches. London: Academic press.

Cerwén, G., Wingren, C., \& Qviström, M. (2016). Evaluating soundscape intentions in landscape architecture: A study of competition entries for a new cemetery in Järva, Stockholm. Journal of Environmental Planning and Management. doi:10.1080/09640568.2016.1215969.

Cross, P., \& Hopwood, C. (2007). Stop smoking: 52 brilliant ideas to kick the habit for good. Oxford: Infinite Ideas.

Hartig, T., Kaiser, F. G., \& Bowler, P. A. (1997). Further development of a measure of perceived environmental restorativeness. Uppsala.

Kaplan, R. \& Kaplan, S. (1989). The experience of nature: a psychological perspective, New York, Cambridge University press.

Kaplan, R. (200I). The Nature of the View from Home: Psychological Benefits. Environment and Behavior, 33(4), 507-542. https://doi.org/10.1 I77/00I39160I21973II5

Kaplan, S. (200I). Meditation, Restoration, and the Management of Mental Fatigue. Environment and Behavior, 33(4), 480-506. https://doi.org/I0.1I77/00I39160I21973106

Kim, S, \& Shanahan, J. (2003) "Stigmatizing smokers: public sentiment toward cigarette smoking and its relationship to smoking behaviors", Journal of Health communication, Volume 8: 343367. 
Klein, G, A., Calderwood, R,, \& Macgregor, D. (1989). Critical decision method for eliciting knowledge. IEEE Transactions on Systems, Man and Cybernetics, 19(3), 462-472.

Lee, C., Yong, H., Borland, R., Mcneill, A., \& Hitchman, S. C. (2018). Acceptance and patterns of personal vaporizer use in Australia and the United Kingdom: Results from the International Tobacco Control survey. Drug and Alcohol Dependence, I85, I42-148. doi:10.1016/j.drugalcdep.2017.12.018.

Lee, K., Sargent, L. D., Williams, K., Williams, N., \& Johnson, K. (2017). Green micro-breaks: Viewing workplace nature improves mood and performance. Academy of Management Proceedings, 2017(I), I 1996. doi:10.5465/ambpp.2017.247.

Lincoln, Y. S., \& Guba, E. G. (1985) “Naturalistic inquiry”. Beverly Hills, CA: Sage Publications, Inc. Louka, P., Maguire, P., Evans, P., Worrell. (2006) "Representations of smoking and experiences of disapproval in UK and Greek smokers." Journal of Health Psychology, I I (3) $44|-45|$.

Loukas, A., Garcia, M. R., Gottlieb, N, H. (2006). Texas college students' opinions of nosmoking policies, secondhand smoke, and smoking in public places. J Am Coll Health. 55, $27-$ 32.

Massarik, F. (198I). "The interviewing process re-examined" In Reason P., Rowan J. (eds.) Human Inquiry: A Source book of New Paradigm Research. Chichester John Wiley \& Sons.

Nyborg, K., \& Rege, M. (2003). "On social norms: The evolution of considerate smoking behavior", Journal of Economic Behavior and Organization, 52(3), 323-340.

Quercia, D., Aiello, L.M., Schifanella, R., McLean K. (20I5). Smelly maps: the digital life of urban smellscapes. In Int. AAAI Conf. on Web and Social Media (ICWSM), Oxford, UK, 26-29 May 2015.

Subasinghe, C. (2012). Shelters of sustainability: Reconfiguring post-Tsunami recovery via selflabor practices. International Journal of Architecture, Engineering and Construction, I (3), I55- I62.

Sureda, X., Fernandez, E., Lopez, M.J., et al (2013). Second-hand tobacco smoke exposure in open and semi-open settings: a systematic review. Environ Health Perspect. 121, 766-773.

Thrasher, James F., Bentley, M, (2006) "Stress in the workplace: past, present and future" In Dunham, J. (eds.) Public Health Report, 12I, London: Whurr publishers.

Ulrich, R. S. (1999) "Effects of gardens on health outcomes: Theory and research". In C. C. Marcus and M. Barnes (eds.), Healing Gardens. New York: John Wiley.

Varna, G. (20I4). Measuring Public Space: The Star Model. London: Routledge, https://doi.org//0.4324/978/3/5594408.

Wolfson, M., McCoy, T, P., Sutfin E, L. (2009). College students' exposure to secondhand smoke. Nicotine Tob Res. II, 977-984. 